\title{
Dietary Patterns and the Intake of Trace Elements in People with Hypertension: A Cross-Sectional Study
}

\author{
Seyedeh Neda Mousavi ${ }^{1}$ (D), Fatemeh Hassani ${ }^{2}$ (D), Masoumeh Namadian*2 ${ }^{\text {iD }}$
}

1. Zanjan Metabolic Diseases Research Center, Zanjan University of Medical Sciences, Zanjan, Iran

2. Social Determinants of Health Research Center, Zanjan University of Medical Sciences, Zanjan, Iran

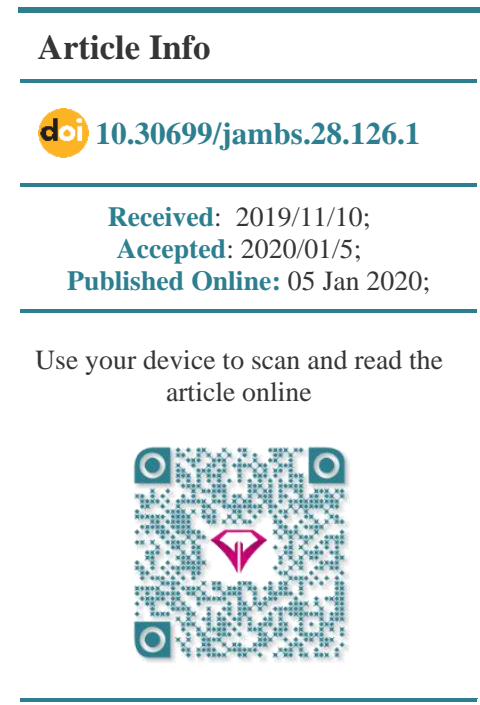

Corresponding Information: Masoumeh Namadian

Social Determinants of Health Research Center, Zanjan University of Medical Sciences, Zanjan, Iran E-Mail: $\underline{\text { m.namadian@zums.ac.ir }}$

\begin{abstract}
Background \& Objective: Dietary patterns and the consumption of some macronutrients could influence hypertension as a public health problem. This study was conducted to identify dietary patterns and compare the intake of some micronutrients, as well as food groups, according to the Dietary Approach to Stop Hypertension (DASH) guidelines.
\end{abstract}

Materials \& Methods: This cross-sectional study assessed the dietary patterns of 101 people with mild to moderate hypertension who were randomly selected among outpatients attending hospital clinics and health centres at Zanjan. Food intake data were collected using the food frequency questionnaire (FFQ) and three-day food diaries. Factor analyses and binary logistic regression were used to identify dietary styles and the associations between types of dietary patterns and hypertension, adjusted for covariates.

Results: Two main dietary patterns were identified, including the DASH-style dietary pattern and the modern dietary pattern which contains high intakes of fast foods, junk foods, animal fat, organ meat, chicken, tea, and coffee. A greater odds ratio for hypertension (odds ratio: 3.95; 95\% CI: 0.91-17.2) was found at the first quartile of the modern pattern compared to the last one, adjusted for confounding variables. Also, patients at the last quartile of the DASH-style pattern received significantly more sodium $(P=0.02)$. Hypertensive patients consumed more sodium and less potassium, calcium, and magnesium than given in the DASH recommendations for both identified dietary patterns.

Conclusion: Two main dietary patterns were found in hypertensive patients. Considering both dietary patterns and micronutrient intake in prevention programs for hypertensive patients is suggested. Future research is recommended.

Keywords: Dietary Approach to Stop Hypertension (DASH), Hypertension, Magnesium, Potassium, Sodium

\section{Introduction}

Hypertension (HTN) is considered a silent killer as it can cause cardiovascular disease (CVD), stroke, renal diseases, and even death (1). Trends suggest an increase in adults suffering from high blood pressure by 2025 (2). It has been proven that HTN is a multifactorial public health concern with multiple genetic, environmental and lifestyle implications $(3,4)$. Moreover, evidence shows that an unhealthy diet and unhealthy behavior are associated with increased odds of HTN (5). Nutritional transitions in dietary choices from a traditional (natural) to a Western-style diet has led to increases in the incidence and prevalence rates of chronic diseases such as HTN (6). Diet is the most important component of blood pressure (BP) control. Since food items are consumed in combination, and because of the interaction among nutrients, it is applied the dietary pattern to be measured along with nutrient intakes. A dietary pattern consisting of various foodstuffs can reflect a habitual food pattern and nutrient intake to explain the relations between diet and various diseases (7). Past studies have revealed that the vegetarian pattern has a protective effect, while the Western-style diet has been related to a higher risk for HTN (8). The Dietary Approaches to Stop Hypertension (DASH) diet is recommended by the American Heart Association and the National Institutes of Health in the USA for managing BP and protecting heart health (9). In this dietary approach, the increased intake of fruits, vegetables, and low-fat dairy products is suggested, and foods that are high in saturated fat is discouraged which would result in lower total dietary fat as well as cholesterol (10). A large body of evidence has demonstrated the benefits of the DASH diet on BP, plasma glucose, lipid profiles, and CVD mortality due 
to its higher potassium, calcium, and magnesium intake and lower sodium intake (11-15). Evidence supports the idea that dietary potassium, calcium, and magnesium intake are lower in hypertensive patients compared to healthy people (16).

Due to the high incidence and prevalence of cardiovascular diseases in the Iranian population (17) and the strong association between diet and cardiovascular diseases (18), the assessment of dietary patterns in people with high blood pressure is important in achieving better management of hypertension. As dietary patterns are different among various cultures due to differences in food types, preferences, and religions (19), further research is needed to clarify the association between dietary patterns and high blood pressure in different countries. Iran is a multi-cultural country with various dietary habits. To the best of our knowledge, there is no evidence comparing the dietary patterns or effective nutrient intakes to the DASH recommendations in the city of Zanjan, nor have their associations with blood pressure been investigated. Therefore, this study was conducted to assess dietary patterns and their associations with systolic and diastolic blood pressures (SBP and DBP) as well as lipid profiles in hypertensive patients. Additionally, nutrient intakes were compared to the DASH recommendations in order to find solutions in planning programs for hypertensive patients in this region.

\section{Materials and Methods}

\section{Study Population, Setting, and Design}

This cross-sectional study, which was carried from June to September 2018, assessed 101 people with mild to moderate hypertension who had participated in a randomized clinical trial about HTN (IRCT20180224038850N1), and were randomly selected among outpatients attending to the Vali-e-Asr Hospital, Shafyieh, and health centers of Zanjan University of Medical Sciences, Iran. The present study was performed in accordance to the ethical standards as laid down in the Declaration of Helsinki, and ethical approval was obtained from the Research Committee of Zanjan University of Medical Sciences (Code Number: IR.ZUMS.REC.1396.302). Patients aged between 18 and 45 years with mild HTN (20) (SBP 140-159 mmHg, and DBP 90-99 $\mathrm{mmHg}$ ), or moderate HTN (20) (SBP 160-179 $\mathrm{mmHg}$, and DBP 100-109 mmHg) whose hypertension was previously diagnosed by physicians, were included in the study. Patients with a history of angina pectoris, type 2 diabetes, renal diseases in addition to pregnant and lactating people were excluded from the study. Participants on a special diet and intake of dietary supplements were also excluded from the study.

\section{BP, Physical Activity and Stress Measures}

The SBP and DBP were measured using the Microlife AG1-40 pressure gauge $(0.1 \mathrm{mmHg}$ accuracy). Physical activity (PA) was assessed using the short form of the International Physical Activity Questionnaire (IPAQ), which measures the physical activity in the last seven days (21). The PA level was converted to minutes per week and then reported as Met/Minutes/Week multiplying the amount of physical activity (minutes/week) by the coefficients (3.3 for walking, 4 for average activity, and 8 for intense activity). PA less than $599 \mathrm{Met} / \mathrm{min} / \mathrm{week}, 600$ to $2999 \mathrm{Met} / \mathrm{min} / \mathrm{week}$, and more than $3000 \mathrm{Met} / \mathrm{min} /$ week were considered as poor, moderate and desirable PA, respectively. Stress was assessed using the Cohen's perceived stress scale with the highest score of 56 and the lowest score of zero $(22,23)$. In the current study information about taking Antihypertensive medicine, physical activity and stress were collected among other confounding factors.

\section{Dietary Intake}

Dietary intake of all participants was collected. Also, Food intake was obtained using the Food Frequency Questionnaire (FFQ) (24) through face to face interviews and 3-day food records (two regular days and one holiday). Frequency consumption of food items was recorded in a day, week, month and year pattern. The weekly, monthly and yearly consumption were converted to daily form by coefficients of 0.14 , 0.032 and 0.0027 , respectively. Food items were grouped into 20 food groups (Table 1) based on similarities in the nutrient profile to determine dietary patterns. Dietary intake data were analyzed using the N4 software (Nutritionist 4, First Data Bank, San Bruno, CA, USA).

\section{Anthropometric and Biochemical Parameters}

The weight was measured for subjects wearing minimal clothing using a Beurer-PS160 digital weigh bridge (100 g). The participants' height was measured using meter in an standing position without shoes, while their shoulders were in normal position. The waist circumference was assessed with a suitable strip meter (with accuracy of $5 \mathrm{~mm}$ ) at the end of the normal exhalation in the area between the iliac and lower rib without pressure on the body surface. Body Mass Index (BMI) was calculated using the weight division by kilograms per square meter. Fasting venous blood samples $(3 \mathrm{cc}$ ) were taken from each participant to measure blood lipid profile using an auto analyzer.

\section{Statistical Analysis}

In order to derive the dietary patterns, the Principle Component Analysis (PCA) was used and the 48 items of FFQ were divided into 20 food groups/items (25). The maximum likelihood and varimax rotation (the rotated loading factor matrix) were used for exploratory factor analysis. The three principal factors were extracted with eigenvalues higher than one. The scree plot of eigenvalues was used to determine the number of factors to retain (26). According to previous studies (27-29), the derived dietary patterns were labeled according to the food item/groups with an absolute factor loading greater than 0.2. The component scores were computed for all identified dietary patterns to determine the extent to 
which each subject complies with the identified dietary patterns. Then, the scores were summed after standardizing each variable to mean $=0$ and $\mathrm{SD}=1$, and were weighted with a coefficient score for the corresponding component. A higher score for the dietary pattern was considered as high intake of food staffs/groups for the assessed diet, and a lower score was considered as low intake. Final analysis was performed by classifying the subjects into quartiles by considering the lowest component score as the reference.

Statistical tests were performed using the SPSS 16 (SPSS Inc., Chicago, Ill., USA). The mean and standard deviation (SD) were used to describe the numeric data, and $\mathrm{P}$-value $<0.05$ was considered as statistically significant. The Kolmogorov Smirnov test was used to check the normal distribution of the variables. Chisquare and independent sample t-tests (or MannWhitney) were used to compare qualitative and quantitative variables between the quartiles of each food pattern, respectively. To assess the interactions between covariates (e.g. age, sex, waist circumference, BMI, stress, antihypertensive drug intakes, physical activity, and dietary pattern on the SBP and DBP, as well as TG and TC) a binary logistic regression model was used in which dependent variables were coded as a nominal variable (above the $50^{\text {th }}$ percentile or below the $50^{\text {th }}$ percentile). It is recommended that the minimum acceptable sample size to test the overall fit of regression models be $50+8 \mathrm{k}$, where $\mathrm{k}$ is the number of predictors
(30). Therefore, with 8 predictors/ co-variates, as used in this study, the required sample size would be 104, indicating that the sample size is sufficient for doing the binary logistic regression model.

\section{Compliance with Ethical Standards}

Informed consent was achieved from all participants before data collection and getting blood samples. Ethical approval was obtained from the Research Committee of Zanjan University of Medical Sciences (Code Number: IR.ZUMS.REC.1396.302).

\section{Results}

\section{Identified Dietary Patterns}

Eight dietary patterns were identified, in which the first and the second one explained $21.94 \%$ of variances in blood pressure. These patterns are named as follows: 1- the DASH-style dietary pattern including high consumption of the legumes, soybean, fresh/dried /cooked vegetables, fruits and natural fruit juices, eggs, nuts, seeds fish, breads and grains ; 2- the modern dietary pattern containing high intake of fast foods, junk foods, animal fat, organ meat, chicken, tea and coffee. Food groups and their factor loading are presented in Tables 1 and $\underline{2}$.

Table 1. Food groups used in factor analysis

\begin{tabular}{|c|c|}
\hline Food groups & Food items \\
\hline Breads \& grains & All kind of breads, wheat, barely, corn \\
\hline Rice & Rice \\
\hline Fast foods & $\begin{array}{l}\text { Pizza, hamburger, sandwiches, fried potato ,processed meat such as sausages, hot dog, } \\
\text { salami }\end{array}$ \\
\hline $\begin{array}{l}\text { Restaurant's diets \& Canned } \\
\text { Foods }\end{array}$ & All kind of restaurant's \& canned Foods \\
\hline Dairy products & Milk, cheese, yogurt, dried whey \\
\hline Liquid Oil & All types of liquid oils, except olive oil \\
\hline Olive and olive oil & Olive and olive oil \\
\hline $\begin{array}{l}\text { Vegetable hydrogenated oils, } \\
\text { mayonnaise }\end{array}$ & Solid Oils, margarine, mayonnaise \\
\hline Animal fats & Ghee, butter, cream, rump \\
\hline Organ Meats & Organ meats (kidney, liver, ...) \\
\hline Red meat & Beef, lamb \\
\hline Egg & Egg \\
\hline Fish & All types of fishes \\
\hline Chicken & Chicken \\
\hline Nuts and seeds & All of nuts and seeds \\
\hline Legumes \& soybean & all of beans, peas, lentil, soybean \\
\hline $\begin{array}{l}\text { Fresh, dried and cooked vegetables, } \\
\text { fruits and natural fruit juices }\end{array}$ & $\begin{array}{l}\text { All of raw, cooked and frozen vegetables including potato, cucumber, tomato, kale, onion, } \\
\text { garlic, carrot, turnip, and all green leafy vegetables and all of fresh fruits and natural fruit juices }\end{array}$ \\
\hline Junk foods & All salted foods (Pickles, sour, chips, ...) \\
\hline Tea and coffee & Black/green tea and coffee \\
\hline Sweets and sweet beverages & $\begin{array}{l}\text { Cakes and cookies, chocolates, biscuits, desserts, jam, jelly, honey, sugary soft drinks, } \\
\text { Pepsi, liquor, soda, nectar, alcohol and beer }\end{array}$ \\
\hline
\end{tabular}


Table 2. Factor loading of food groups

\begin{tabular}{|ccc|}
\hline Food groups & DASH-style & Modern pattern \\
\hline $\begin{array}{c}\text { Legumes \& soybean } \\
\text { fresh, dried and cooked vegetables, } \\
\text { ruits and natural fruit juices }\end{array}$ & 0.733 & \\
\hline Egg & 0.654 & \\
\hline Nuts and seeds & 0.547 & \\
\hline Fish & 0.354 & \\
\hline Breads \& grains & 0.246 & 0.732 \\
\hline Fast foods & 0.218 & 0.706 \\
\hline Junk foods & & 0.319 \\
\hline Animal fats & & -0.317 \\
\hline Organ Meats & & 0.256 \\
\hline Chicken & & 0.217 \\
\hline Tea and coffee & & $\mathbf{8 . 0 3 \%}$ \\
\hline Total variance: $\mathbf{2 1 . 9 4 \%}$ & $\mathbf{1 3 . 9 1 \%}$ & \\
\hline
\end{tabular}

Table 3. Demographic, anthropometric and clinical variables in the quartiles of dietary patterns

\begin{tabular}{|c|c|c|c|c|c|c|c|}
\hline \multirow{2}{*}{\multicolumn{2}{|c|}{$\begin{array}{l}\text { Dietary pattern } \\
\text { Variables }\end{array}$}} & \multicolumn{2}{|c|}{ DASH-style } & \multirow{2}{*}{ P-value $\uparrow$} & \multicolumn{2}{|c|}{ Modern pattern } & \multirow{2}{*}{$\begin{array}{c}\text { P. } \\
\text { value }\end{array}$} \\
\hline & & Q1 & Q4 & & Q1 & Q4 & \\
\hline \multicolumn{2}{|c|}{ Age, yr } & $40.8 \pm 5.3$ & $40.6 \pm 3.6$ & 0.9 & $40.2 \pm 4.6$ & $40.9 \pm 3.1$ & 0.49 \\
\hline \multirow{2}{*}{ Sex } & Men & $6(26.1 \%)$ & $6(26.1 \%)$ & \multirow{2}{*}{0.8} & $5(21.7 \%)$ & $5(21.7 \%)$ & \multirow{2}{*}{0.6} \\
\hline & Women & $19(24.4 \%)$ & $19(24.4 \%)$ & & $20(25.6 \%)$ & $20(25.6 \%)$ & \\
\hline \multirow{2}{*}{ Marital status } & Single & $2(66.7 \%)$ & 0 & \multirow{2}{*}{0.3} & $1(33.3 \%)$ & $1(33.3 \%)$ & \multirow{2}{*}{0.8} \\
\hline & Married & $23(23.5 \%)$ & $25(25.5 \%)$ & & $24(24.5 \%)$ & $24(24.5 \%)$ & \\
\hline \multirow{3}{*}{$\begin{array}{l}\text { Education } \\
\text { level }\end{array}$} & Under diploma & $16(25 \%)$ & $17(26.6 \%)$ & \multirow{3}{*}{0.9} & $17(26.6 \%)$ & $17(26.6 \%)$ & \multirow{3}{*}{0.09} \\
\hline & Diploma & $7(28 \%)$ & $5(20 \%)$ & & $5(20 \%)$ & $7(28 \%)$ & \\
\hline & University & $2(16.7 \%)$ & $3(25 \%)$ & & $3(25 \%)$ & $1(8.3 \%)$ & \\
\hline \multirow{2}{*}{ Drug } & Yes & $21(\% 28)$ & $18(\% 24)$ & \multirow{2}{*}{0.5} & $20(26.7 \%)$ & $17(22.7 \%)$ & \multirow{2}{*}{0.8} \\
\hline & No & $4(\% 15.4)$ & $7(\% 26.9)$ & & $5(19.2 \%)$ & $8(30.8 \%)$ & \\
\hline \multicolumn{2}{|c|}{$\mathrm{SBP}, \mathrm{mmHg}$} & $144.4 \pm 10.9$ & $143 \pm 12.7$ & 0.68 & $144.4 \pm 10.1$ & $142.7 \pm 10.5$ & 0.42 \\
\hline \multicolumn{2}{|c|}{ DBP, mmHg } & $88.3 \pm 10.5$ & $88.8 \pm 7.25$ & 0.85 & $88.8 \pm 10.1$ & $86.9 \pm 8$ & 0.82 \\
\hline \multicolumn{2}{|c|}{ Weight, kg } & $77.2 \pm 11.8$ & $77.5 \pm 13.7$ & 0.83 & $79.9 \pm 11.6$ & $74.5 \pm 11.9$ & 0.11 \\
\hline \multicolumn{2}{|c|}{ BMI, kg/m2 } & $29.7 \pm 4.3$ & $29.09 \pm 5.07$ & 0.63 & $31.2 \pm 5.4$ & $28.8 \pm 3.9$ & 0.07 \\
\hline \multicolumn{2}{|c|}{ Waist circumference, $\mathrm{cm}$} & $101.7 \pm 9.8$ & $98.6 \pm 11.9$ & 0.3 & $103.1 \pm 10.8$ & $99.3 \pm 9.5$ & 0.2 \\
\hline \multicolumn{2}{|c|}{$\begin{array}{c}\text { PA } \\
\text { Met/min/week }\end{array}$} & $4192.5 \pm 6088.1$ & $4132.3 \pm 5508.6$ & 0.97 & $3893.3 \pm 7203.02$ & $2559.5 \pm 3221.7$ & 0.4 \\
\hline \multicolumn{2}{|c|}{ Stress } & $27.04 \pm 6.6$ & $26.6 \pm 5.4$ & 0.79 & $25.3 \pm 7.1$ & $28.52 \pm 4.5$ & 0.06 \\
\hline \multicolumn{2}{|c|}{$\mathrm{TC}, \mathrm{mg} / \mathrm{dl}$} & $146.04 \pm 23$ & $145.2 \pm 27.5$ & 0.91 & $136.52 \pm 25.1$ & $162.4 \pm 66.8$ & 0.07 \\
\hline \multicolumn{2}{|c|}{$\mathrm{TG}, \mathrm{mg} / \mathrm{dl}$} & $175.1 \pm 108.3$ & $159.6 \pm 80.5$ & 0.58 & $177.2 \pm 69.8$ & $134.2 \pm 55.2$ & 0.02 \\
\hline
\end{tabular}

$\dagger p$ value assessed by independent sample t-test (or Mann-Whitney) for quantitative and Chi-square test for qualitative variables

Q1: the first quartile; Q4: the last quartile; SBP: systolic blood pressure; DBP: diastolic blood pressure; PA: physical activity level; TC: total cholesterol; TG: triglyceride 
Table 4. Modeling of blood pressure and lipid profile in two major identified dietary patterns

\begin{tabular}{|c|c|c|c|c|c|c|c|c|c|c|}
\hline & \multicolumn{10}{|c|}{ Quartiles of dietary pattern } \\
\hline & \multirow{2}{*}{$\begin{array}{l}\text { Q1 } \\
\text { Ref }\end{array}$} & \multicolumn{3}{|c|}{ Q2 } & \multicolumn{3}{|c|}{ Q3 } & \multicolumn{3}{|c|}{ Q4 } \\
\hline & & $\beta^{*}$ & $95 \% \mathrm{CI}$ & $\mathrm{P}^{\dagger}$-value & $\beta$ & $95 \% \mathrm{CI}$ & P-value & $\beta$ & $95 \% \mathrm{CI}$ & P-value \\
\hline DASH style & & & & & & SBP & & & & \\
\hline Unadjusted & 0 & 0.56 & $0.17 ; 1.78$ & 0.32 & 1.01 & $0.33 ; 3.08$ & 0.98 & 0.66 & $0.21 ; 2.09$ & 0.48 \\
\hline Adjusted (a) $^{(a)}$ & 0 & 0.53 & $0.14 ; 1.94$ & 0.34 & 1.2 & $0.32 ; 4.25$ & 0.8 & 0.72 & $0.21 ; 2.55$ & 0.6 \\
\hline \multirow[t]{2}{*}{ Adjusted $^{(b)}$} & 0 & 0.6 & $0.15 ; 2.2$ & 0.42 & 1.15 & $0.31 ; 4.2$ & 0.84 & 0.67 & $0.2 ; 2.43$ & 0.54 \\
\hline & \multicolumn{10}{|c|}{ DBP } \\
\hline Unadjusted & 0 & 0.57 & $0.14 ; 2.35$ & 0.44 & 2.2 & $0.66 ; 7.4$ & 0.2 & 0.95 & $0.26 ; 3.48$ & 0.93 \\
\hline Adjusted ${ }^{(a)}$ & 0 & 0.57 & $0.13 ; 2.47$ & 0.45 & 2.03 & $0.54 ; 7.61$ & 0.29 & 1.03 & $0.27 ; 4.02$ & 0.96 \\
\hline \multirow[t]{2}{*}{ Adjusted $^{(b)}$} & 0 & 0.64 & $0.14 ; 2.92$ & 0.57 & 2.06 & $0.54 ; 7.89$ & 0.29 & 0.96 & $0.24 ; 3.85$ & 0.95 \\
\hline & \multicolumn{10}{|c|}{ TG } \\
\hline Unadjusted & 0 & 0.78 & $0.25 ; 2.4$ & 0.66 & 0.7 & $0.22 ; 2.25$ & 0.55 & 0.92 & $0.29 ; 2.9$ & 0.89 \\
\hline Adjusted $^{(a)}$ & 0 & 0.61 & $0.18 ; 2.14$ & 0.44 & 0.73 & $0.19 ; 2.76$ & 0.64 & 1.08 & $0.29 ; 3.98$ & 0.9 \\
\hline \multirow[t]{2}{*}{ Adjusted $^{(b)}$} & 0 & 0.54 & $0.15 ; 1.98$ & 0.35 & 0.68 & $0.17 ; 2.66$ & 0.57 & 0.83 & $0.21 ; 3.32$ & 0.79 \\
\hline & \multicolumn{10}{|c|}{ TC } \\
\hline Unadjusted & 0 & 0.78 & $0.25 ; 2.4$ & 0.66 & 0.85 & $0.26 ; 2.7$ & 0.78 & 0.65 & $0.21 ; 2.06$ & 0.46 \\
\hline Adjusted $^{(a)}$ & 0 & 0.85 & $0.26 ; 2.77$ & 0.78 & 1.01 & $0.29 ; 3.49$ & 0.99 & 0.7 & $0.21 ; 2.31$ & 0.55 \\
\hline Adjusted $^{(b)}$ & 0 & 0.71 & $0.2 ; 2.48$ & 0.6 & 0.9 & $0.24 ; 3.32$ & 0.87 & 0.47 & $0.13 ; 1.7$ & 0.25 \\
\hline Modern & & & & & & SBP & & & & \\
\hline Unadjusted & 0 & 0.84 & $0.26 ; 2.7$ & 0.76 & 1.3 & $0.42 ; 4.03$ & 0.64 & 1.78 & $0.57 ; 5.57$ & 0.32 \\
\hline Adjusted $^{(a)}$ & 0 & 0.98 & $0.25 ; 3.75$ & 0.97 & 2.2 & $0.59 ; 8.03$ & 0.24 & 3.3 & $0.81 ; 13.24$ & 0.09 \\
\hline \multirow[t]{2}{*}{ Adjusted $^{(b)}$} & 0 & 1.09 & $0.28 ; 4.35$ & 0.89 & 2.12 & $0.57 ; 7.95$ & 0.26 & 3.95 & $0.91 ; 17.2$ & 0.04 \\
\hline & \multicolumn{10}{|c|}{ DBP } \\
\hline Unadjusted & 0 & 0.56 & $0.16 ; 1.92$ & 0.35 & 0.53 & $0.16 ; 1.81$ & 0.31 & 0.59 & $0.17 ; 2.03$ & 0.4 \\
\hline Adjusted $^{(a)}$ & 0 & 0.43 & $0.11 ; 1.7$ & 0.23 & 0.56 & $0.15 ; 2.08$ & 0.4 & 0.66 & $0.17 ; 2.56$ & 0.55 \\
\hline \multirow[t]{2}{*}{ Adjusted $^{(b)}$} & 0 & 0.49 & $0.12 ; 1.99$ & 0.32 & 0.53 & $0.14 ; 2.04$ & 0.36 & 0.77 & $0.19 ; 3.23$ & 0.73 \\
\hline & \multicolumn{10}{|c|}{ TG } \\
\hline Unadjusted & 0 & 0.4 & $0.12 ; 1.27$ & 0.12 & 0.51 & $0.16 ; 1.66$ & 0.26 & 0.22 & $0.06 ; 0.75$ & 0.01 \\
\hline Adjusted $^{(a)}$ & 0 & 0.25 & $0.06 ; 1.02$ & 0.04 & 0.64 & $0.17 ; 2.42$ & 0.52 & 0.35 & $0.08 ; 1.37$ & 0.1 \\
\hline \multirow[t]{2}{*}{ Adjusted $^{(b)}$} & 0 & 0.29 & $0.06 ; 1.23$ & 0.09 & 0.64 & $0.16 ; 2.46$ & 0.5 & 0.39 & $0.09 ; 1.6$ & 0.2 \\
\hline & \multicolumn{10}{|c|}{ TC } \\
\hline Unadjusted & 0 & 1.77 & $0.56 ; 5.57$ & 0.32 & 2.31 & $0.72 ; 7.37$ & 0.15 & 2.13 & $0.66 ; 6.88$ & 0.2 \\
\hline Adjusted $^{\text {(a) }}$ & 0 & 2.12 & $0.59 ; 7.6$ & 0.24 & 3.9 & $1.07 ; 14.2$ & 0.03 & 3.38 & $0.9 ; 12.65$ & 0.07 \\
\hline Adjusted $^{(b)}$ & 0 & 3.43 & $0.85 ; 13.8$ & 0.08 & 4.43 & $1.11 ; 17.7$ & $\mathbf{0 . 0 3}$ & 5.44 & $1.28 ; 23.17$ & 0.002 \\
\hline
\end{tabular}

Adjusted $^{(a)}$ : adjusted for age, sex, education, antihypertensive drug intakes, waist circumference and BMI;

Adjusted ${ }^{(b)}$ : Adjusted ${ }^{(a)}$ plus physical activity and stress

DASH: dietary approach to stop hypertension; SBP: systolic blood pressure; DBP: diastolic blood pressure; TG: triglyceride; TC: total cholesterol

${ }^{\dagger}$ Assessed by logistic regression model; $\beta$ : Estimated regression coefficients of logistic regression model 
Table 5. Comparing Food groups and micronutrients intakes in the first (Q1) and last quartiles (Q4) of two major dietary patterns

\begin{tabular}{|c|c|c|c|c|c|c|}
\hline \multirow[b]{2}{*}{ variables } & \multicolumn{2}{|l|}{ DASH-style } & \multirow{2}{*}{$\begin{array}{l}\text { P- } \\
\text { value }\end{array}$} & \multicolumn{2}{|c|}{ Modern pattern } & \multirow{2}{*}{$\begin{array}{l}\text { P- } \\
\text { value }\end{array}$} \\
\hline & Q1 & Q4 & & Q1 & Q4 & \\
\hline Energy, kcal/day & $1860.3 \pm 430.8$ & $1897.1 \pm 504.4$ & 0.82 & $1869.6 \pm 378.3$ & $1775.4 \pm 375.1$ & 0.46 \\
\hline Sodium, mg/day & $3338.7 \pm 978.7$ & $2949.2 \pm 320.2$ & 0.02 & $3493.3 \pm 907.6$ & $3092.9 \pm 348.7$ & 0.09 \\
\hline Potassium, mg/day & $2011.9 \pm 694.5$ & $2030.4 \pm 915.6$ & 0.94 & $1916.5 \pm 690.1$ & $1786.4 \pm 541.3$ & 0.54 \\
\hline Magnesium, mg/day & $168.9 \pm 46.8$ & $157.7 \pm 43.4$ & 0.47 & $161.7 \pm 45.3$ & $155.2 \pm 39.5$ & 0.65 \\
\hline Calcium, mg/day & $629.3 \pm 173.7$ & $598.6 \pm 163.5$ & 0.60 & $590.6 \pm 138.8$ & $565.3 \pm 112.7$ & 0.55 \\
\hline Grains and breads, serving/day & $12.97 \pm 3.6$ & $11.46 \pm 3.21$ & 0.21 & $12.4 \pm 2.8$ & $13.01 \pm 3.98$ & 0.62 \\
\hline Fruits, serving/day & $2.08 \pm 2.34$ & $2.01 \pm 1.75$ & 0.90 & $2.16 \pm 2.3$ & $1.88 \pm 1.6$ & 0.67 \\
\hline Vegetables, serving/day & $0.95 \pm 0.76$ & $0.95 \pm 0.73$ & 0.99 & $0.74 \pm 0.54$ & $0.89 \pm 0.55$ & 0.43 \\
\hline Red meat, serving/day & $0.66 \pm 0.57$ & $0.88 \pm 0.87$ & 0.38 & $0.79 \pm 0.8$ & $1.01 \pm 0.78$ & 0.40 \\
\hline Chicken and fish, serving/day & $1.85 \pm 0.83$ & $1.36 \pm 0.82$ & 0.09 & $1.90 \pm 0.8$ & $1.27 \pm 0.76$ & 0.02 \\
\hline Legumes and nuts, serving/day & $0.72 \pm 0.96$ & $0.54 \pm 0.52$ & 0.51 & $1.01 \pm 1.3$ & $0.75 \pm 0.66$ & 0.46 \\
\hline Dairy, serving/day & $0.82 \pm 0.64$ & $0.53 \pm 0.60$ & 0.17 & $0.49 \pm 0.34$ & $0.64 \pm 0.4$ & 0.21 \\
\hline Oils, serving/day & $6.57 \pm 1.86$ & $7.13 \pm 1.33$ & 0.53 & $6.78 \pm 2.42$ & $7.47 \pm 2.9$ & 0.44 \\
\hline
\end{tabular}

$\dagger \mathrm{p}$ values are reported according to the independent sample t-test

Q1: the first quartile; Q4: the last quartile

Demographic, and Biochemical Measures Between the First and Last Quartiles

With the exception of TG and stress at the modern dietary pattern, which were significantly higher at the Q4 compared to the Q1 $(P=0.02$ and $P=0.06$, respectively), no significant difference was observed in the other variables $(P>0.05)$ (Table 3$)$.

The analysis of the final logistic regression with adjustment for the co-variates including age, sex, stress, waist circumference, physical activity, BMI and blood lipids, revealed that the modern dietary pattern was positively associated with increased SBP significantly $(P=0.04)$, and the odds of having higher blood pressure (SBP) with the modern dietary pattern in Q4 would increase by 3.95 (95\% CI: 0.91-17.2) times greater compared to patients in Q1 $(P=0.04)$.

In the adjusted model, the results showed that the hypertensive patients in Q3 and Q4 of modern dietary pattern had higher TC levels by 4.43 times $(95 \% \mathrm{CI}$ : $1.11 ; 17.7, P=0.03$ ) and 5.44 times (95\% CI: 1.28 ; 23.17, $P=0.002)$ respectively, compared to the reference quartile (Table 4$)$.

Micronutrients Intake Compared to the Recommended Amounts at the DASH Diet

Our results showed that hypertensive patients consumed higher sodium, and lower potassium, magnesium, calcium in their diet compared to the recommended amounts in the DASH diet $(<2300 \mathrm{mg}$, $4700 \mathrm{mg}, 500 \mathrm{mg}$ and $1200 \mathrm{mg}$, respectively). At the
DASH-style group, patients significantly received more sodium at the first quartile than the last one $(P=0.02)$. At the Modern-style group, patients received lower white meats (fish and chicken) at the last quartile compared to the first one $(P=0.02)$ (Table 5) .

\section{Discussion}

The main aim of this study was to determine the dietary patterns of people with mild and moderate hypertension and their associations with systolic blood pressure (SBP), diastolic blood pressure (DBP), and lipid profile. Micronutrient intake was also assessed according to the DASH recommendations. To the best of our knowledge, this is the first study to determine dietary patterns as well as the dietary and micronutrient intake of hypertensive patients compared to the DASH recommendations in Zanjan, Iran. Zanjan is one of the biggest cities located in the northwest of Iran. It is a cold city located in a mountainous area where the Turkish language and culture inform a special lifestyle and dietary habits. Therefore, food preferences are different from other regions. In this study, two main dietary patterns (with high variances) were identified in hypertensive patients. The DASH-style pattern consisted of a high consumption of legumes, soybean, fresh/dried/cooked vegetables, fruits and natural fruit juices, eggs, nuts, seeds fish, breads, and grains; meanwhile, the modern pattern included the high intake 
of fast foods, junk foods, animal fat, organ meat, chicken, tea, and coffee. The results showed that after adjusting for co-variates, the odds of the first quartile (Q1) of the modern dietary pattern of increasing SBP is 3.95 times (95\% CI: 0.91-17.2) greater than that of the last quartile (Q4), representing a significant difference. In the modern dietary pattern, TC was significantly higher at the third and last quartiles compared to Q1 ( $P=0.03$ and $P=0.02$, respectively) after adjusting for all co-variates. In the adjusted model, hypertensive patients at Q3 and Q4 of the modern dietary pattern had higher TC levels by 4.43 times (95\% CI: $1.11 ; 17.7, P=0.03$ ) and 5.44 times (95\% CI: 1.28; 23.17, $P=0.002)$, respectively, when compared to the reference quartile (Q1). Hypertensive patients with a DASH-style pattern, meanwhile, received higher amounts of sodium at Q1 compared to Q4. Patients at the last quartile of the modern dietary pattern consumed less white meat (fish and chicken) than the first one (Q1). Hypertensive patients in both major identified dietary patterns consumed more sodium and less calcium, potassium and magnesium than indicated in the DASH recommendations.

There are few studies about dietary patterns in hypertensive patients, and no study was performed in the city of Zanjan prior to now. In one study done on 973 hypertensive patients, the relationship among three types of dietary patterns - including Western-style (loin meat, margarine, coffee, nuts, sweets and desserts, seasonings, and soda), healthy style (poultry, low-fat and high-fat dairy products, vegetables, legumes, whole grains, fish, and olives), and the traditional form (eggs, tea, juices, refined grains, nuts, pickles, solid and liquid oils, sugar, salt, and spices) — and BP were assessed. The traditional style did not significantly correlate with high BP, while the Western and healthy dietary styles had direct and inverse associations with high BP. The target population, sample size, and identified dietary patterns in the above-mentioned study were different from the current one (31). Three dietary patterns - including the healthy dietary pattern (rich in fruits, olives, dairy, chicken and fish, liquid oils, and canned foods), the Western pattern (rich in carbohydrate drinks, prepared foods, salmon snacks, mayonnaise, and organ meats), and the mixed dietary pattern (rich in legumes, potatoes, eggs, red meat, tea, and coffee) were identified in a study on hypertensive patients, and the healthy style was inversely related to elevated SBP in the adjusted models. They concluded that following a healthy dietary pattern reduced the risk of high BP by $26 \%$ (32). In the present study, the DASH-style pattern was not associated with SBP or DBP; however, the modern pattern increased the risk of high SBP. One reason for this might be the elevated sodium and lowered potassium, magnesium, and calcium intakes in the DASH-style dietary pattern. Hypertensive patients with the DASH-style dietary pattern received more sodium during the first quartile. All patients in both identified dietary patterns consumed more sodium and less potassium, calcium, and magnesium than indicated in the DASH recommenddations. This suggests that additional information about dietary patterns, food groups, and major elements such as calcium, magnesium, potassium, and sodium is necessary to provide useful recommendations for hypertensive patients.

A 12-week clinical trial on Australian men compared the effects of a DASH diet - containing $\geq 4$ servings of fruits, $\geq 4$ servings of vegetables, $\geq 3$ servings of low-fat dairies, and $\sim 4$ servings of fat per day, as well as $\geq 3$ servings of fish, $\sim 1$ cup of legumes, and $\leq 2$ servings of meat per week, plus $\sim 30$ gr of unsalted nuts 4 times per week - with a conventional low-fat diet. It reported that patients on the DASH diet showed $5.2 \pm 1.8 \mathrm{mmHg}$ and $4.8 \pm 1.3 \mathrm{mmHg}$ reductions in their SBP and DBP, respectively (33). In a 9-week clinical trial, the effect of the DASH diet-along with $\sim 2$ alcohol drinks, $\sim 3$ caffeinated beverages, and $2300 \mathrm{mg}$ sodium per day, accompanied by increased exercise-was compared with no intervention in American hypertensive patients (SBP: 130-170 and DBP: 80-100). The likelihood of reducing BP using the DASH diet was 9.5 times $(95 \%$ CI: $-14.5,-4.5)$ and 5.3 times (95\% CI: $-8.5,-2.1)$ higher than when modern diet was provided for SBP and DBP, respectively (34).

Also, an Iranian clinical trial compared the impacts of the DASH and usual diabetic diets on the SBP and DBP of type 2 diabetic patients. In the DASH diet, patients received $\sim 5$ servings of fruits, $\sim 7$ servings of vegetables, $\sim 3$ servings of dairy, $\sim 5$ servings of grains, and $\sim 2300$ mg of sodium per day; meanwhile, participants on the usual diabetic diet consumed $\sim 3$ servings of fruits, $\sim 4$ servings of vegetables, $\sim 2$ servings of dairy, $\sim 3$ servings of whole grains, and $\sim 3000 \mathrm{mg}$ of sodium per day. The results showed a probability of reducing blood pressure by 10.5 times $(95 \% \mathrm{CI}:-19.2,1.8)$ and 8.8 times $(95 \%$ CI: -17.1, -0.6) for SBP and DBP, respectively, when compared to the usual diabetic diet (35). In this crosssectional study, hypertensive patients consumed lower levels of vegetables, fruits, dairies, legumes, fish, and poultry, but higher levels of sodium and fat. The DASHstyle diet was not associated with reductions in SBP and DBP. Interestingly, patients on this style of diet consumed more sodium and less potassium and magnesium. Therefore, it seems that merely identifying dietary patterns is not sufficient to reach the applied 
recommendations in these patients and that the amounts of sodium, potassium, magnesium, and calcium being consumed should also be considered.

The current study had some limitations. First, as this study was cross-sectional, it could not determine the causal-relationship between dietary patterns and hypertension. Second, the likelihood of information bias (recall bias) is high when using the FFQ for data collection, which limits the reliability of findings for patient's dietary pattern. Also, the participants were recruited from Zanjan, a city in the north-west of Iran with special dietary habits and food preferences and a different culture. Therefore, it might not be generalized to other places and population.

\section{Conclusion}

Two main dietary patterns (i.e., the DASH-style dietary pattern and the modern dietary pattern) were dominant in the nutrition patterns of patients with hypertension. The results showed that the modern dietary pattern was associated with higher SBP and, interestingly, that the DASH-style dietary pattern was not associated with lower levels of SBP or DBP. Hypertensive patients in both identified dietary patterns consumed more sodium and less potassium, calcium, and magnesium than expressed in the DASH recommendations. The evidence in this study suggests that following a healthy diet and achieving the recommended intake of effective nutrients such as calcium, magnesium, potassium, and sodium is necessary to reach beneficial outcomes. Another indirect but important finding of this study was that many hypertensive people receiving treatment for hypertension did not comply with the recommended healthy diet to control their high blood pressure. Hypertension with the high prevalence and incidence is known as a public health problem globally. The key role of a healthy diet (including micronutrients) in controlling high blood pressure, and the insufficient information available about the dominant diet in hypertensive people show that there is still room to conduct further research to address these issues. Future research to replicate the present findings using a prospective design is recommended.

\section{Acknowledgments}

This article is part of the MSc dissertation in MedicalSurgical Nursing approved by Social Determinants of Health research center, and sponsored by the Research Vice-Chancellor of Zanjan University of Medical
Sciences (Grant Number: A-11-147-10). The researchers gratefully acknowledge all the people with high blood pressure who participated in the study; without them there would be no data.

\section{Conflict of Interest}

Authors declared no conflict of interest.

\section{References}

1. Irazola VE, Gutierrez L, Bloomfield G, et al. Hypertension prevalence, awareness, treatment, and control in selected LMIC communities: results from the NHLBI/UHG Network of centers of excellence for chronic diseases. Glob Heart. 2016;11(1):47-59.

[DOI:10.1016/j.gheart.2015.12.008]

2. Kearney PM, Whelton M, Reynolds K, Muntner $\mathrm{P}$, Whelton PK, He J. Global burden of hypertension: analysis of worldwide data. The lancet. 2005;365(9455):217-23. [DOI:10.1016/S0140-6736(05)17741-1]

3. Kuneš $\mathrm{J}$, Zicha $\mathrm{J}$. The interaction of genetic and environmental factors in the etiology of hypertension. Physiol Res. 2009;58(Suppl 2):S33-S41.

4. Falkner B. Hypertension in children and adolescents: epidemiology and natural history. Pediatr Nephrol. 2010;25(7):1219-24. [DOI:10.1007/s00467-009-1200-3]

5. Eaton SB, Eaton III SB. An evolutionary perspective on human physical activity: implications for health. Comp Biochem Physiolo A Mol Integr Physiol. 2003;136(1):153-9. [DOI:10.1016/S1095-6433(03)00208-3]

6. Karppanen H, Karppanen P, Mervaala E. Why and how to implement sodium, potassium, calcium, and magnesium changes in food items and diets? J Hum Hypertens. 2005;19(S3):S10. [DOI:10.1038/sj.jhh.1001955]

7. Hu FB. Dietary pattern analysis: a new direction in nutritional epidemiology. Curr Opin Lipidol. 2002;13(1):3-9. [DOI:10.1097/00041433200202000-00002]

8. Sun J, Buys N, Hills A. Dietary pattern and its association with the prevalence of obesity, hypertension and other cardiovascular risk factors among Chinese older adults. Int J Environ Res Public Health. 2014;11(4):3956-71. [DOI:10.3390/ijerph110403956]

9. Jones NR, Forouhi NG, Khaw K-T, Wareham NJ, Monsivais P. Accordance to the dietary approaches to stop hypertension diet pattern and 
cardiovascular disease in a British, populationbased cohort. Eur J Epidemiol. 2018;33(2):23544. [DOI:10.1007/s10654-017-0354-8]

10. Appel LJ, Moore TJ, Obarzanek E, et al. A clinical trial of the effects of dietary patterns on blood pressure. New England J Med. 1997;336(16):1117-24.

\section{[DOI:10.1056/NEJM199704173361601]}

11. Akita S, Sacks FM, Svetkey LP, Conlin PR, Kimura G. Effects of the dietary approaches to stop hypertension (DASH) diet on the pressurenatriuresis relationship. J Hypertens. 2003;42(1):8-13.

[DOI:10.1161/01.HYP.0000074668.08704.6E]

12. Sacks FM, Svetkey LP, Vollmer WM, et al. Effects on blood pressure of reduced dietary sodium and the dietary approaches to stop hypertension (DASH) diet. New England J Med. 2001;344(1):3-10.

[DOI:10.1056/NEJM200101043440101]

13. Geleijnse JM, Kok FJ, Grobbee DE. Blood pressure response to changes in sodium and potassium intake: a metaregression analysis of randomised trials. J Hum Hypertens. 2003;17(7):471. [DOI:10.1038/sj.jhh.1001575]

14. Blumenthal JA, Babyak MA, Hinderliter A, et al. Effects of the DASH diet alone and in combination with exercise and weight loss on blood pressure and cardiovascular biomarkers in men and women with high blood pressure: the ENCORE study. Arch Intern Med. 2010;170(2):126-35.

[DOI:10.1001/archinternmed.2009.470]

15. George SM, Ballard-Barbash R, Manson JE, et al. Comparing indices of diet quality with chronic disease mortality risk in postmenopausal women in the women's health initiative observational study: evidence to inform national dietary guidance. Am J Epidemiol. 2014;180(6):616-25. [DOI:10.1093/aje/kwu173]

16. Struijk EA, May AM, Wezenbeek NL, et al. Adherence to dietary guidelines and cardiovascular disease risk in the EPIC-NL cohort. Int J Cardiol. 2014;176(2):354-9. [DOI:10.1016/j.ijcard.2014.07.017]

17. Salehi-Abargouei A, Maghsoudi Z, Shirani F, Azadbakht L. Effects of dietary approaches to stop hypertension (DASH)-style diet on fatal or nonfatal cardiovascular diseases-incidence: a systematic review and meta-analysis on observational prospective studies. J Nutr. 2013;29(4):611-8

[DOI:10.1016/j.nut.2012.12.018]

18. Asemi Z, Samimi M, Tabassi Z, Sabihi S-s, Esmaillzadeh A. A randomized controlled clinical trial investigating the effect of DASH diet on insulin resistance, inflammation, and oxidative stress in gestational diabetes. $\mathbf{J}$ Nutr. 2013;29(4):619-24.

[DOI:10.1016/j.nut.2012.11.020]

19. Ugwuja EI, Ejikeme BN, Ugwu NC, Obeka NC, Akubugwo EI, Obidoa O. Comparison of plasma copper, iron and zinc levels in hypertensive and non-hypertensive pregnant women in Abakaliki, South Eastern Nigeria. Pak J Nutr. 2010;9(12):1136-40. [DOI:10.3923/pjn.2010.1136.1140]

20. Jacobs DR, Tapsell LC. Food synergy: the key to a healthy diet. Proc Nutr Soc. 2013;72(2):200-6. [DOI:10.1017/S0029665112003011]

21. Vasheghani-Farahani A, Tahmasbi M, Asheri H, Ashraf H, Nedjat S, Kordi R. The persian, last $7-$ day, long form of the international physical activity questionnaire: translation and validation study. Asian J Sports Med. 2011;2(2):106. [DOI:10.5812/asjsm.34781]

22. Madhumitha M, Naraintran S, Manohar C. Influence of stress and socio demographic factors on hypertension among urban adults in North Karnataka. Asian J Biomed Pharmaceut Sci. 2014;4(38):23-26. [DOI:10.15272/ajbps.v4i38.630]

23. Bahram-Khani M, Ali-Pour A, Janbozorgi M, Barzegar-Ghazi K. Effectiveness of muscle progressive relaxation on perceived stress in patients with essential hypertension. J Clin Psychol. 2011;3(9):79-88.

24. Mohammadifard N, Sajjadi F, Maghroun M, Alikhasi H, Nilforoushzadeh F, Sarrafzadegan N. Validation of a simplified food frequency questionnaire for the assessment of dietary habits in Iranian adults: Isfahan Healthy Heart Program, Iran. ARYA atherosclerosis. 2015;11(2):139-147

25. Kleinbaum DG, Kupper L, Muller KE. Applied regression analysis and other multivariable methods. PWS Publishing Co. Boston, MA, USA. 1988

26. Fransen HP, May AM, Stricker MD, et al. A posteriori dietary patterns: how many patterns to retain? J Nutr. 2014;144(8):1274-82. [DOI:10.3945/jn.113.188680]

27. Atkins JL, Whincup PH, Morris RW, Lennon LT, Papacosta O, Wannamethee SG. Dietary patterns and the risk of CVD and all-cause mortality in older British men. Br J Nutr. 2016;116(7):124655. [DOI:10.1017/S0007114516003147]

28. Smith AD, Emmett PM, Newby P, Northstone K. Dietary patterns obtained through principal components analysis: the effect of input variable quantification. Br J Nutr. 2013;109(10):1881-91. [DOI:10.1017/S0007114512003868] 
29. Slattery ML. Analysis of dietary patterns in epidemiological research. Appl Physiol Nutr Metab. 2010;35(2):207-10. [DOI:10.1139/H10$\underline{006}]$

30. Field A. Discovering statistics using SPSS. 2nd edition, SAGE publications, UK:London. 2005

31. Roosta S, Falahi E, Cheraghi M. Association between hypertension and dietary patterns among adults residents of Khorramabad. Iran J Endocrinol Metab. 2015;16(5):356-64.

32. Mottaghi A, Hosseini Esfahani F, Mirmiran P, Azizi F. Assessment of relationship between dietary patterns and incidence of hypertension: Tehran Lipid and Glucose Study. Iranian J Endocrinol Metab. 2015;16(6):433-40.
33. Nowson CA, Worsley A, Margerison C, Jorna MK, Godfrey SJ, Booth A. Blood pressure change with weight loss is affected by diet type in men. Am J Clin Nutr. 2005;81(5):983-9. [DOI:10.1093/ajen/81.5.983]

34. Miller ER, Erlinger TP, Young DR, et al. Results of the diet, exercise, and weight loss intervention trial (DEW-IT). J Hypertens. 2002;40(5):612-8. [DOI:10.1161/01.HYP.0000037217.96002.8E]

35. Azadbakht L, Fard NRP, Karimi M, et al. Effects of the dietary approaches to stop hypertension (DASH) eating plan on cardiovascular risks among type 2 diabetic patients: a randomized crossover clinical trial. Diabetes Care. 2011;34(1):55-7. [DOI:10.2337/dc10-0676]

\section{How to Cite This Article:}

Mousavi S N, Hassani F, Namadian M. Dietary Patterns and the Intake of Trace Elements in People with Hypertension: A Cross-Sectional Study. J Adv Med Biomed Res. 2020; 28 (126) :1-10

\section{Download citation:}

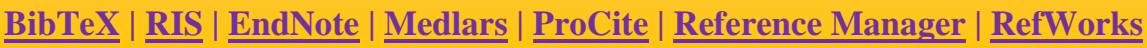

\section{Send citation to:}

Mendeley $2 \underline{\text { Zotero }}$ (i) RefWorks $\underline{\text { RefWorks }}$ 